\title{
Trajetória da formação de professores de ciências para educação inclusiva em Goiás, Brasil, sob a ótica de participantes de uma rede colaborativa
}

\author{
Trajectory of the training of science teachers \\ for inclusive education in Goiás, Brazil, from the perspective \\ of participants in a collaborative network
}

\author{
Lidiane de Lemos Soares Pereira $^{1}$. Claudio Roberto Machado Benite ${ }^{2}$ \\ - Juliana Caixeta Padilha ${ }^{3}$. Maria Luiza Mendes ${ }^{4}$. \\ Eveline Borges Vilela-Ribeiro ${ }^{5}$ - Anna Maria Canavarro Benite ${ }^{6}$
}

\begin{abstract}
Resumo: Apresenta-se uma investigação com elementos de uma pesquisa participante que objetivou apresentar o cenário da formação de professores de ciências no âmbito da educação inclusiva utilizando interações discursivas produzidas em reuniões de uma rede de pesquisa no estado de Goiás. Os resultados permitiram analisar a política de educação inclusiva no estado de Goiás, bem como refletir sobre como o ensino de ciências pode contribuir para a formação de cidadãos dentro dessa escola inclusiva.
\end{abstract}

Palavras-chave: Formação de professores. Ensino de ciências. Educação inclusiva.

Abstract: We present an investigation using participatory research that aims to present the scenario of the training of science teachers in education using inclusive discursive in meetings of a research network in the state of Goiás Our results allowed us to rethink the policy of inclusive education the state of Goiás, and reflect on how science education can contribute to the formation of a citizen in this inclusive school.

Keywords: Science Teachers Training. Science teaching. Inclusive education.

\footnotetext{
${ }^{1}$ Instituto Federal de Educação, Ciência e Tecnologia de Goiás, Avenida Pedro Ludovico, s/n, Reny Cury, CEP 75131-457, Anápolis, GO, Brasil. E-mail<lidilemossp@yahoo.com.br>

2,5,6 Instituto de Química, Universidade Federal de Goiás (UFG), Goiânia, GO, Brasil.

${ }^{3,4}$ Gerência de Ensino Especial, Secretaria de Estado de Educação, Cultura e Esporte (SEDUC), Goiânia, GO, Brasil.
} 


\section{A formação de professores de ciências na perspectiva da educação inclusiva}

Os cursos de licenciatura em ciências, como os demais cursos das universidades brasileiras, seguem, de modo geral, o modelo da "racionalidade técnica" (SCHÖN, 1987). Dessa forma, supõe-se que, a partir do conhecimento teórico, se torne mais fácil aprender a técnica para utilizá-la na solução de problemas (BENITE, 2009).

Neste cenário, a educação inclusiva é uma realidade concreta na política de educação nacional, e se configura como uma problemática discutida pelos currículos de formação de professores, uma vez que a racionalidade técnica já não consegue responder muitos anseios. Por sua vez, os Parâmetros Curriculares Nacionais (PCN) enfatizam que existe uma necessidade do desenvolvimento de competências básicas para o exercício da cidadania. No caso das ciências, o desenvolvimento do cidadão está relacionado ao aprimoramento da capacidade de as pessoas lidarem com problemas e questões de ordem científica, tecnológica e ambiental, sabendo pensar, discutir e decidir sobre o tema (SANTOS; SCHNETZLER, 2003). Nesse sentido, os PCN orientam que é preciso refletir sobre a compreensão e a utilização dos conhecimentos científicos para explicar o funcionamento do mundo, bem como planejar, executar e avaliar as ações de intervenção na realidade (BRASIL, 2000). Portanto, o ensino de ciências tem intrincada relação com as questões do efetivo domínio de quais direitos e deveres estão imbuídos do ser cidadão.

Dessa forma, acreditamos que o ensino de ciências tem potencial para contribuir com a formação de um cidadão capaz de elaborar pensamentos autônomos e críticos, de modo a poder decidir por si mesmo, frente às diferentes circunstâncias da vida. Aprender ciências, logo, independe do fato de este educando apresentar necessidades educacionais especiais ${ }^{7}$ ou não. Entretanto, para que o ensino de ciências possa formar cidadãos indistintamente, é necessário repensarmos a formação de professores para atuar na perspectiva da educação inclusiva. Concordamos com Vilela-Ribeiro e Benite (2010, p. 587) que:

Assim como em todas as outras áreas do conhecimento, o professor de ciências (Química, Física e Biologia) deve estar preparado para lidar com as diferenças dos alunos em sala de aula, inclusive com aqueles com necessidades educativas especiais, e, por isso, a importância de se discutirem as políticas educacionais de formação inicial de professores de ciências.

Assumindo as exigências da sociedade do conhecimento, um dos modelos de formação de professores defende o conceito de professor-reflexivo, que considera a reflexão e a investigação sobre a prática docente como necessidades formativas, tornando-se constitutivas das próprias atividades do professor, como condições para o seu desenvolvimento profissional. Segundo Zeichner (1998, p. 215):

\footnotetext{
${ }^{7}$ De acordo com a Resolução CNE/CB no 02/2001 (BRASIL, 2001), estudantes com necessidades educacionais especiais são aqueles que possuem quaisquer dificuldades de aprendizagem ou limitações, podendo estar relacionadas a causas orgânicas ou não.
} 
[...] quando pensamos no nosso ensino cotidiano, também estamos a criar saberes. As estratégias que usamos nas salas de aula encarnam teorias e práticas sobre o modo de entender os valores educacionais. Professores estão sempre a teorizar, à medida que estão confrontando-se com os vários problemas pedagógicos, por exemplo, diferença entre as suas expectativas e os resultados.

Acrescenta-se que importa a necessidade de repensar a formação dos formadores de professores de ciências, já que estes são responsáveis pela formação inicial. Por isso, concordamos com Vilela-Ribeiro e Benite (2010, p. 588), quando destacam que:

[...] para essa realidade se efetivar, os cursos de licenciatura em ciências devem estar preparados para formar professores para inclusão, ou seja, os professores formadores devem ser os primeiros a se prepararem, com vistas que só serão formados profissionais aptos para inclusão se os próprios formadores tiverem percepção sobre o assunto.

Uma das alternativas é considerar a formação inicial e continuada de professores como uma parceria colaborativa formada por grupos assimétricos, cabendo, aos professores formadores, viabilizarem, tornarem acessível, de forma útil e substantiva, aos professores do Ensino Médio e aos futuros professores, inúmeras contribuições epistemológicas e teórico-metodológicas de pesquisas na área de Educação. Isto porque tais contribuições, quando apresentadas e discutidas à luz das descrições e características das práticas usuais dos professores, podem, gradativamente, auxiliá-los a melhor compreendê-las e reformulá-las, tornando-se mais conscientes de seus limites e possibilidades (SCHNETZLER, 2002).

Consideramos que “[...] a formação do professor não só passa por um processo de crescimento pessoal e aperfeiçoamento profissional, mas também pela transformação da cultura escolar, que inclui a idealização, implementação e consolidação de novas práticas participativas e gestão democrática" (ECHEVERRIA; BENITE; SOARES, 2007, p. 6).

Portanto, defendemos que uma alternativa de ação é a criação de redes de formação participada, que permitam compreender a globalidade do sujeito, assumindo a formação como um processo interativo e dinâmico (NÓVOA, 1995). A troca de experiências e a partilha de saberes de forma assimétrica consolidam espaços de formação mútua, nos quais cada professor é chamado a desempenhar, simultaneamente, o papel de formador e de formando.

É nessa perspectiva que a Rede Goiana de Pesquisa em Educação Especial/Inclusiva (RPEI) se configura como espaço de discussão conceitual e formação de professores, por meio de ações refletidas, enquanto rede social, reunindo um conjunto de pessoas ou representantes de grupos que possuem conexões de algum tipo com um ou com todos os integrantes da rede (BENITE et al., 2009).

A RPEI é formada por uma parceria dialógica que conta com as participações: da Universidade Federal de Goiás (professores formadores e alunos de pós-graduação e graduação), especificamente, o Instituto de Química; do Programa de Mestrado em Educação em Ciências e Matemática (a perspectiva acadêmica); da Secretaria de Estado da Educação de Goiás, por 
meio da Coordenação de Educação Especial (a perspectiva política e gestora), e a Associação de Surdos de Goiânia (a perspectiva da comunidade).

Partindo desse pressuposto, a interação reflexiva (SCHÖN, 1998) sobre a prática pedagógica é caracterizada pela observação, análise e reflexão crítica conjunta, mostrando-se importante instrumento para a promoção de mudanças nos relatos e ações do professor, sob a mediação do pesquisador. Com isso, a RPEI possui o intuito de promover esse processo interacional que busca a reflexão da prática pedagógica como princípio articulador e privilegia a formação do professor pesquisador de sua própria ação no âmbito da educação inclusiva. Nessa perspectiva, o objetivo principal da RPEI é produzir uma "reflexão autoformadora" (NÓVOA, 1995) na tentativa de contribuir para a superação de um profissional que apenas transmita conhecimentos produzidos por outros, constituindo-se sujeito ativo na construção e reconstrução de novas práticas pedagógicas. Assim, objetivamos resgatar, por meio das interações discursivas produzidas na RPEI, quais foram as principais ações formativas em ciências no que diz respeito à educação inclusiva, nos últimos doze anos, em Goiás, e qual a percepção dos participantes da RPEI sobre essas políticas.

\section{A educação inclusiva no estado de Goiás: 15 anos de história}

A discussão sobre a inclusão é recorrente em todas as esferas educacionais, pois, mesmo não tendo garantia de cumprimento, as leis exigem a adequação dos sistemas educacionais para a integração e o atendimento dos alunos com necessidades educacionais especiais.

Entretanto, cabe ressaltar a importância da inclusão escolar dessas pessoas, não apenas pela sua integração e permanência junto aos demais, mas pela reorganização do sistema educacional, intencionando a rediscussão de nossas concepções, crenças, paradigmas educacionais na busca pelo exercício da cidadania, respeitando a identidade própria de cada sujeito (GLAT; NOGUEIRA, 2003).

Segundo dados de 2008 do Instituto Nacional de Estudos e Pesquisas Educacionais Anísio Teixeira (INEP), a situação da educação inclusiva atual no Brasil encontra-se com avanços significativos no que diz respeito ao aumento do número de matrículas dos alunos com necessidades educacionais especiais nas escolas regulares, oriundos de escolas ou classes especiais. Avanços como este são consequência de uma política de reestruturação do sistema educacional vigente, que visa, também, um novo olhar para a formação inicial e continuada dos professores, além de melhores condições de trabalho, incluindo os meios de acessibilidade destes educandos.

Fundamentados no exposto acima, pode-se inferir que a função das escolas inclusivas é a inclusão escolar de todas as pessoas excluídas do processo educacional nas escolas ditas não inclusivas, de modo que estudantes possam se assumir como agentes ativos, cidadãos atuantes na/e da própria vida. Nessa perspectiva, cabe definir que educação inclusiva se refere a todos que estão à margem do processo educacional e que não tiveram oportunidade e acesso ao sistema educacional.

Concordamos com Stainback e Stainback (1999), que o processo de inclusão demanda três componentes interdependentes: (a) a rede de apoio, que é o componente organizacional, formado por equipes e indivíduos que se apoiam; (b) a consulta cooperativa e o trabalho em equipe, que representam o componente de procedimento que envolve indivíduos trabalhan- 
do juntos para implementar ações contemplando os alunos em ambientes integrados, e (c) a aprendizagem cooperativa, que é o componente do ensino onde cria-se um ambiente propício para os alunos se desenvolverem inseridos com alunos de diferentes habilidades e interesses.

A educação inclusiva propõe que a formação continuada da comunidade escolar aconteça mediante reflexões críticas acerca de toda discussão sobre: inclusão escolar, promoção de debates, compartilhamento de experiências, realização de ciclos de estudos, intencionando intervenção nas ações dos mesmos e, consequentemente, no processo de aprendizagem de todos os alunos.

No estado de Goiás, o processo de inclusão escolar teve início em 1999, por meio do Programa Estadual de Educação para a Diversidade numa Perspectiva Inclusiva (PEEDI). Cabe ressaltar que segundo Sassaki (2003, p. 34):

[...] aquele início foi o ponto final de um longo processo de organização da Educação Especial como um sistema paralelo ao sistema regular de ensino, processo esse que foi respaldado em leis e políticas públicas, tanto federais quanto estaduais, bem como em quase 50 anos de práticas integrativas realizadas em Goiás por iniciativas governamentais e particulares.

Portanto, como assinala o autor, o estado de Goiás passava da fase de integração para a fase de inclusão. Existe uma diferença de sentido entre integração e inclusão. Embora ambas se refiram à incorporação das pessoas com necessidades educacionais especiais nas salas de aula, a primeira entende que o problema para a incorporação da pessoa é a própria pessoa ou sua limitação, eximindo, assim, a escola de buscar soluções para a questão. A inclusão, em oposição à integração, considera que todas as pessoas possuem diferentes necessidades, dessa maneira, a escola, como se apresenta atualmente, está limitada, uma vez que o processo de ensino-aprendizagem é que deve estar adaptado às distintas individualidades dos seus estudantes (BUENO, 1999). Assim, a partir da fase de inclusão, as escolas estaduais foram adequadas considerando a realidade do aluno, matriculando-o e assegurando seu acesso e permanência nas classes regulares (SASSAKI, 2003).

O PEEDI foi uma proposta que surgiu durante um evento intitulado "Fórum Estadual de Educação de Goiás”, realizado no município de Goiânia, em 1998, após a discussão, pelo público, de um documento preliminar intitulado "Uma Nova Proposta Educacional com Base nos Princípios da Inclusão".

A proposta inicial do PEEDI consistiu em operacionalizar o programa em quatro fases: Sensibilização, Implantação, Expansão e Consolidação. Segundo Goiás (2004), o programa foi elaborado em consonância com a política educacional do Estado de Goiás e a legislação vigente, e foi fundamentado no princípio de educação para todos, ressaltando que as estruturas, programas e projetos desencadeados pelo PEEDI deveriam assegurar apoio tanto aos profissionais quanto aos alunos, pautados sempre na política inclusiva (GOIÁS, 2004).

O PEEDI deu início no estado com a execução de dez projetos, a saber:

Escola Inclusiva (projeto-chave, transformando escolas comuns em inclusivas), Prevenir (em parceria com a Secretaria de Saúde, na prevenção 
e detecção precoce de deficiências), Hoje (atendimento educacional em hospitais), Espaço Criativo (inclusão pela arte em parceria com o Centro Livre de Artes, na capital e no interior), Depende de Nós (participação da família na inclusão de seus filhos), Comunicaşão (melhoria das habilidades de comunicação de alunos surdos e cegos), Despertar (desenvolvimento de alunos com indícios de altas habilidades), Caminhar Juntos (interfaces com as Superintendências de Educação Infantil e Ensino Fundamental, e parcerias com as redes municipais de ensino), Refazer (para alunos autistas) e Unidades de Referência (ressignificação das escolas especiais). (SASSAKI, 2003, p. 35-36. Grifos do autor.)

Estes projetos deveriam ser desenvolvidos pelas escolas, visando o desenvolvimento de ações, e que essas fossem discutidas pela equipe escolar e contempladas no Regimento Escolar e nos Projetos Políticos Pedagógicos das escolas.

Pautados em registros da Secretaria de Educação do estado de Goiás, percebemos que houve um aumento considerável no número de matrículas de alunos com necessidades educacionais especiais no Estado de Goiás, passando de 4.895 em 2000 para 11.992 em 2006 (GOIÁS, 2006). Em valores numéricos, este dado representa um aumento de 240,6\% no número de matrículas em seis anos, desde a criação do PEEDI. Entretanto, cabe considerar que não há como existir uma escola inclusiva de qualidade sem que haja a melhoria na estrutura física e capacitação de professores e técnicos para atender, adequadamente, os alunos que dela usufruem. Sendo assim, apesar de avanços obtidos pela implantação do PEEDI ainda hoje, doze anos depois, ainda nos questionamos quanto à situação da educação inclusiva no estado.

\section{A escolha metodológica}

Sob o pressuposto do Materialismo Histórico Dialético, a pesquisa se configura com elementos de uma Pesquisa Participante (PP), pois combina investigação social, trabalho educacional e ação (HALL, 1979).

A RPEI se reúne quinzenalmente na dinâmica de discussões orientadas por textos da comunidade científica, acordados pela RPEI. Esta opção foi feita porque o grupo acredita que a formação profissional se dá de forma contínua, e não factual ou pontual, como propostas de cursos de atualização de curta duração.

Segundo Vigotsky (2001), somos constituídos, enquanto sujeitos em formação, nas interações sociais, isto é, possuímos identidade própria por meio das interações estabelecidas ao longo de nossas vidas, em processos sistematicamente mediados pelo outro, representativos de vivências e saberes diversificados que se requerem em relação de reciprocidade. Nos contextos e interações sociais, são produzidos sentidos e significados formadores da mente humana, da consciência do ser humano, de tudo o que o caracteriza como um ser específico, com determinadas características de um ser individual.

Os instrumentos de coleta de dados utilizados nessa pesquisa foram: a gravação em áudio e vídeo, que, posteriormente, foi transcrita, e o diário de campo, onde são registradas anotações inerentes aos encontros. 
Segundo Bakhtin (2006), a construção de sentido é dialógica por natureza, onde as enunciações devem ser analisadas na perspectiva de quem produz e, também, na perspectiva dos interlocutores, presentes ou não no diálogo (MACHADO, 1999). Para o autor:

Todo signo, como sabemos, resulta de um consenso entre indivíduos socialmente organizados no decorrer de um processo de interação. Razão pela qual as formas dos signos são condicionadas tanto pela organização social de tais indivíduos como pelas condições em que a interação acontece. Uma modificação destas formas ocasiona uma modificação no signo. (BAKHTIN, 2006, p. 45)

Ainda segundo o autor, a compreensão do processo de significação não acontece somente por meio dos sons emitidos na fala, mas por meio da subjetividade de cada indivíduo durante o diálogo. Sendo assim, é somente por meio das interações que as enunciações podem ser compreendidas.

A análise do processo dialógico referente aos encontros da RPEI só é possível ser compreendida admitindo-se que a RPEI se constitui enquanto grupo socialmente organizado, onde seus atores (total de vinte e cinco) contribuem de forma assimétrica com seus conhecimentos prévios acerca das questões discutidas. Assim, qualquer modificação que venha acontecer na dinâmica do grupo ocasiona modificações na apropriação dos signos gerados a partir das discussões.

A RPEI é composta de cinco professores formadores: PF1, PF2, PF3, PF4 e PF5, quatro alunos de pós-graduação/mestrado: PG1, PG2, PG3 e PG4, quatro alunos de graduação: A1, A2, A3, e A4, e 12 professores da Educação Básica: PM1, PM2, PM3, PM4, PM5, PM6, PM7, PM8, PM9, PM10, PM11 e PM12, estes atuando como gestores da Educação Especial/Inclusiva na Coordenação de Ensino Especial do Estado de Goiás, onde as reuniões vêm acontecendo desde o mês de julho de 2007, após o lançamento do Edital - Programa de Fortalecimento de Redes de Pesquisa da Fundação de Amparo à Pesquisa do Estado de Goiás (FAPEG).

\section{Resultados e discussão}

Apresentamos, aqui, trechos dos diálogos produzidos na RPEI, no período de junho de 2009 a agosto de 2010, durante cinco encontros de trabalho que versaram sobre a formação acadêmica dos professores formadores de professores de ciências do Estado de Goiás, bem como da participação dos mesmos no desenvolvimento e implantação do PEEDI no estado.

O Estado de Goiás, em face das leis maiores que regem o sistema educacional brasileiro, teve de se adequar à realidade nacional implantando a Educação Especial de forma isolada em 1953, por meio da Lei no 926, inaugurando, em 1955, o Instituto Pestalozzi de Goiânia (IPG) para atender aos alunos com necessidades educacionais especiais (ALMEIDA, 2003, p. 17).

Já na década de 1970, iniciou o processo de integração das pessoas com necessidades educacionais especiais no sistema regular de ensino, por meio da inserção de salas especiais em algumas escolas regulares do estado, como podemos observar no diálogo a seguir: 
Pereira, L. L. S. et al.

PM6 - Antes do PEEDI, por volta de 1970, a superintendência funcionava da seguinte forma: "o processo de triagem [avaliação do comprometimento dos alunos] e a avaliação pedagógica funcionavam normalmente". O estado possuía algumas salas especiais, onde se agrupavam os alunos. Eu me recordo que tinha uma sala de surdos em um colégio, não era em todas as escolas, era em algumas escolas que tinham salas especiais, salas de surdos e os demais alunos com outras deficiências eram alocados em outra sala, ou seja, aqueles alunos padronizados. Nas escolas especiais ficavam aqueles que tinham mais um comprometimento intelectual. Existia essa diferença, a escola especial atendia os mais comprometidos e as escolas comuns, regulares, possuiam as salas especiais, isso chamava integração.

PM2 - É verdade, nós da superintendência avaliávamos os alunos e encaminhávamos ou para as classes especiais, onde ficava os alunos com pouco comprometimento, on seja, alunos que possuiam avanços pedagógicos, acadêmicos razoável ou para as escolas especiais, onde ficava os alunos com deficiência moderada ou profunda.

PM6 e PM2 discorrem sobre o cumprimento da Lei $n^{\circ} 5.962 / 71$, que reforma o ensino de $1^{\circ}$ e $2^{\circ}$ graus, e mostram que, em um dos artigos da lei, estabelece-se que alunos com deficiências físicas e mentais devem receber tratamento especial. Quanto a essa década, Mendes (2006, p. 397) faz a seguinte análise:

Foi apenas na década de 1970 que surgiu uma resposta mais contundente do poder público a essa questão [acesso de alunos com necessidades educacionais especiais em escolas regulares]. Possivelmente esse avanço foi decorrência da ampliação do acesso à escola para a população em geral, da produção do fracasso escolar e da conseqüente implantação das classes especiais nas escolas básicas públicas, na época predominantemente sob a responsabilidade dos sistemas estaduais.

A partir da década de 1970, as discussões a respeito da forma como a política educacional neste âmbito era conduzida avançaram e, em 1990, acontece um dos marcos, sendo realizada uma Conferência Mundial em que o assunto central era uma Educação para Todos (UNESCO, 1990). Logo após a realização desta, acontece, em 1994, a Conferência sobre Necessidades Educativas Especiais, culminando na elaboração da Declaração de Salamanca, ressaltando o princípio da igualdade de direitos e o respeito às diferenças.

Esses movimentos foram fundamentais na elaboração da nova Lei de Diretrizes e Bases da Educação Nacional, Lei no 9.394/1996 (BRASIL, 1996), que propõe, em um dos seus capítulos, a discussão da educação especial, trazendo consigo a problemática sobre a educação inclusiva no Brasil.

Acompanhando essa nova discussão, o estado de Goiás elaborou, em 1998, uma reinterpretação da Lei (GOIÁS, 1998), que viria a ser um dos pontos cruciais para essa nova trajetória da educação no nosso estado, como podemos observar na fala de PM2 abaixo:

PM2 - Quando eu me mudei para Goiânia tinha umas salas especiais, o Colemar Natal era uma das escolas que possuía classe especial de surdos. E em 99 com esse 
redimensionamento em 99, com essa mudança de integração para inclusão, esses meninos iriam fazer parte da classe comum, eles iriam para as salas de $5^{a}$ serie à $8^{a}$ serie já com os demais alunos e ai estava nossa maior preocupação, pois a gente falava que eles não iriam dar conta nunca, mas precisavam dar conta e nós também precisávamos dar conta deles.

Assim, em 1999, foram ministrados vários cursos formativos para os próprios professores da rede estadual de ensino (CARVALHO, 2004) visando à qualificação desses profissionais para a educação inclusiva. Deve-se salientar que estas formações promovidas pelo Estado estão fundamentadas na Lei Complementar n. 26 do Estado de Goiás (GOIÁS, 1998), que se comprometeu com essa qualificação, em parceria com as instituições de Ensino Superior do Estado.

$\mathrm{Na}$ época, esses cursos visavam formar, dentre outros, professores em duas modalidades: o professor de recurso, que fornece orientações para o professor regente em conformidade com a antiga Superintendência de Ensino Especial (SUEE), que auxilia o aluno em outro turno; e o professor de apoio, que atua de forma integrada com o professor regente quando se trata de alunos com limitações que dificultam o aprendizado (CARVALHO, 2004). Desta forma, podemos observar, na fala de PM6, a necessidade, na época, desses cursos:

PM6 - [...] no início do programa teve muita formação, teve uma preparação muito grande voltada para um número muito grande de profissionais da educação, principalmente o professor de recurso foi um profissional que na época a gente viu a necessidade dele pra estar orientando, estar formando diante dessas necessidades, estar trabalhando com o professor regente com escola. Então, houve uma formação muito grande de 2000 a 2004, só que esses profissionais, alguns viram a responsabilidade que tinham, a dificuldade que iam enfrentar que não era fácil, e cairam fora, procurando outra função, outros simplesmente por um acesso (progressão automática) porque estava na escola tinham a oportunidade e "Vamos nós pra Caldas Novas fazer o curso", pegava o certificado dava entrada de acesso e depois desapareciam.

Como afirma Sant'ana (2005), para uma formação voltada para a educação inclusiva, somente a utilização de cursos é insuficiente para desenvolver a prática docente, pois esta requer um acompanhamento contínuo de capacitação e reavaliação da prática que os professores estão exercendo em sala da aula, onde o mesmo passa a refletir sobre a sua prática a fim de melhorar o desenvolvimento de sua aula. Ou seja, a formação para a educação inclusiva é um processo gradativo e, desta forma, requer uma reflexão contínua.

\section{Sobre a formação dos formadores de professores de ciências para a inclusão escolar}

[...] a sociedade mudou, mas a escola não acompanhou o seu ritmo de desenvolvimento e o Ensino de Ciências, em contexto escolar, ainda se mostra marcado por limitações típicas ao ensino tradicional. Baseado nas mesmas repetições de conteúdos apenas memorísticos, reitera a maneira linear e fragmentada de organização do conhecimento no currículo es- 
colar, cerceado ao cunho apenas propedêutico, aliado à preparação para concursos e seleções. (HAMES; ZANON; WIRZBICKI, 2006, p. 2)

O Ensino de Ciências ainda hoje, após anos da discussão proposta pelos Parâmetros Curriculares Nacionais, se concretiza de maneira linear e fragmentada, deixando de lado aspectos interdisciplinares e contextuais previstos na Lei de Diretrizes e Bases da Educação Nacional (BRASIL, 1996). Paralela a essa discussão, encontramos o respaldo à garantia de acesso e permanência de alunos com necessidades educacionais especiais em salas de aula regulares, além da seguridade de condições de ensino que inclua esses indivíduos, como exposto no artigo 59 da referida lei: “Os sistemas de ensino assegurarão aos educandos com necessidades especiais: currículos, métodos, técnicas, recursos educativos e organização específicos, para atender às suas necessidades" (BRASIL, 1996).

Entretanto, a clareza registrada nas normativas legais, quando transferida para a execução do ato pedagógico, transforma-se em ações de alto grau de complexidade pelas dificuldades implícitas na sua realização (BENITE et al., 2009). Além disso, se tratando de ensino de ciências, segundo Driver et al. (1999, p. 32):

[...] existem alguns compromissos centrais ligados às práticas científicas e ao conhecimento que têm implicações para o ensino da ciência. Defendemos que, na educação em ciências, é importante considerar que o conhecimento científico é, ao mesmo tempo, simbólico por natureza e socialmente negociado.

A partir desses pressupostos, a tentativa de explicar a ciência por meio de seu ensino esbarra com a alta complexidade exigida para tal, pois, entre ambos, existe a linguagem simbólica própria da área. Consequentemente, esse é um dos aspectos recorrente à fragmentação do ensino como possibilidade de explicá-la. Para Morin (2005, p. 192):

[...] a complexidade pede para pensarmos nos conceitos, sem nunca dá-los por concluídos, para quebrarmos as esferas fechadas, para restabelecermos as articulações entre o que foi separado, para tentarmos compreender a multidimensionalidade, para pensarmos na singularidade com a localidade, com a temporalidade, para nunca esquecermos as totalidades integradoras.

$[\ldots]$

A totalidade é, ao mesmo tempo, verdade e não-verdade, e a complexidade é isso: a junção de conceitos que lutam entre si.

Dessa forma, os problemas colocados frente à realidade estabelecida exigem múltiplos olhares acerca dos fenômenos educacionais, enfocando a necessidade de se formar um professor capaz de compreender a totalidade integradora implícita nesse processo. Com isso, ao se deparar com situações problemáticas, como é o caso da educação inclusiva, a técnica utilizada como solução (proporcionada pelo modelo de formação) vai depender da construção anterior de um problema bem delineado, o que não é, em si, uma tarefa técnica. Quando um profis- 
sional reconhece uma situação como única não pode lidar com ela apenas aplicando técnicas derivadas de sua bagagem de conhecimento teórico (SCHÖN, 1987). Assim, a singularidade das diferentes situações da prática educativa, exige reflexões e soluções adequadas (GONÇALVES; GONÇALVES, 1998).

É no embate com a realidade escolar que as antigas certezas caem por terra e exigem cada vez mais a busca e o entrecruzamento de saberes. É nessa tensão que somos levados a compreender que os paradigmas hegemônicos não fornecem respostas para todas as incógnitas que o cotidiano apresenta, pois a realidade sempre apresentará novas e complexas dificuldades. Das certezas antigas que procuravam a simplificação da prática pedagógica, surge em nós, com grande ênfase, a consciência dos nossos não saberes e, por conseqüência, muitas incertezas e dúvidas. (CAMPOS; PESSOA, 1998, p. 184)

Quando refletimos sobre o contexto da Educação Inclusiva, muitas questões relativas à formação de professores de ciências se tornam presentes. Aliado a isso, temos o desafio de tornar o ensino mais articulado com os interesses e necessidades práticas da maioria dos alunos presentes nas escolas, tendo eles necessidades educacionais especiais ou não.

Portanto, nas duas últimas décadas, o sistema educacional brasileiro tem vivenciado uma transição ensejada pela inclusão escolar. Certamente, as instituições de ensino têm encontrado dificuldades na implementação de novas propostas, a começar pelo diagnóstico das dificuldades de aprendizagem, passando pela urgência da capacitação profissional para atender pedagogicamente essa proposta (BENITE et al., 2009).

Não obstante, paralelo a essa discussão imposta pela proposta da Educação Inclusiva, ainda precisamos avançar com relação à superação do Modelo da Racionalidade Técnica, já que muitos do que estão a promover mudanças no âmbito da educação inclusiva no estado de Goiás foram formados por esse modelo que, ainda hoje, é o modelo que rege a formação de futuros professores, restando, aos que se interessam pela área, fazer cursos de especialização altamente difundidos no Brasil, para suprirem as necessidades, como podemos observar no diálogo abaixo:

PM7 - Eu tenho dois cursos superiores, primeiro fiz letra e depois direito, letras en fiz bacharelado e licenciatura, fiz pós-graduação no Rio de Janeiro em Metodologia do Ensino Superior e somente agora recentemente comecei a fazer cursos na área da Educação Especial, mas interrompi uma pós-graduação em Educação Especial para fazer outra que me interessei, libras, que é a mistura da teoria com prática, $e$ agora estou voltando para terminar educação especial.

PM6 - Minha formação é em letras pela Universidade de Goianésia, hoje Universidade Estadual de Goiás, tenho um pós-graduação pela Universidade Federal de Goiás em Lingua Portuguesa e também pela a UEG em Psicopedagogia e agora estou fazendo uma a distância pela a UNB em Desenvolvimento Humano e Educação Inclusiva e também estou lá na UFG como aluna especial em lingüística. PG5 - Minha área de formação é Ciências Biológicas, Biologia pela UEG. Eu fir. uma pós-graduação em Psicopedagogia também pela UEG e como não foi contem- 
Pereira, L. L. S. et al.

plado em minha formação disciplinas que tratavam da educação especial e inclusiva, fiz. uma pós-graduação em libras e estou no mestrado lá na federal, desenvolvendo pesquisa nessa parte de inclusão também.

PM3 - Eu fiz. licenciatura em história pela UEG e tenho duas especializaçoees, uma em Formação Socioeconômica, feita em Brasilia e outra em Psicopedagogia, feita aqui em Goiânia. Estou fažendo também biologia à distância pela UFG, mas também não me foi contemplado quando me formei em história aspectos da educação especial e inclusiva.

PG3 - Eu sou formada em química pela UEG, me formei em 2007 e até então não havia disciplinas no meu curso que contemplavam a educação especial e inclusiva. Eu me lembro que nossa turma, minha turma de química, foi quem iniciou uma sensibilização, pois tínhamos uma matéria chamada prática e vivência que estava simplesmente na grade para cumprir uma interpretação da lei. Então nós pegamos e reivindicamos quando estávamos na Prática e vivência III, que era só apresentação de projeto, uma disciplina que contemplasse todas as especificidades da Educação Inclusiva ou que pelo menos falasse, que apresentasse para nós, professores, esta questão da diversidade. Só que essa mudança chegou, pelo que me parece, somente depois da minha turma.

Cabe ressaltar que, enquanto a formação inicial ofereceu e ainda oferece ao cenário educacional professores com lacunas em algumas áreas específicas, como a educação especial e inclusiva, a maioria dos professores responsáveis pela formação dos professores de ciências no âmbito da educação inclusiva em Goiás não possui formação específica na área de ciências, e eles foram e são, até hoje, com raras exceções, formados em serviço, tal como se revela nos discursos abaixos:

PM7 - Eu sempre tive vontade de trabalhar com surdos e até aprender a lingua. Eu pensava que devia ser muito triste andar por algum lugar e não achar com quem conversar, e eu como deficiente auditivo não podia deixar acontecer isso. Então, eu fui convidado por uma escola, pois estava precisando de professor lá. Até hoje não entendo muito bem o que aconteceu, pois a diretora me colocou para dar aulas em uma sala de alunos surdos e então eu falei para ela que não dava, que eu nunca tinha trabalhado com crianças com algum tipo de deficiência. Mas, enfim, eu fui para a associação de surdos e sempre buscando me aprimorar me sai muito bem lá. Foi um trabalho muito bom e então desde 94 estou com eles.

PM2 - Eu tive dois alunos surdos no início de minha carreira enquanto professora e na época não sabia o que fazer. Foi tão impressionante, mais a gente aprendeu a conviver. No ensino superior en vim trabalhar com uma menina que ela tinha deficiência mental, que me fez repensar muito e então contribuiu para mudar minha prática e sair em busca de novos conbecimentos.

PM6 - Eu terminei o magistério e já entrei em um concurso da prefeitura da minha cidade e só tinha vagas para a escola especial. Fui a primeira semana todos os dias e diria quando chegava em casa, amanhã eu não vou. Foi um grande desafio, pois eu não tinha experiência e já me colocaram para trabalhar com um aluno autista, sem nenhum tipo de orientação, e ainda era uma criança desorganiz̧ada e agressiva e 
então falava "amanhã eu não volto" e com esse amanhã eu não volto fiquei por nove anos na escola, sempre buscando aprender sobre esse aluno, com a minha prática.

O discurso produzido por PM6, PM7 e PM2 aponta que a formação dos formadores de professores de ciências, no âmbito da educação inclusiva no estado de Goiás, partiu de uma necessidade prática de enfrentar situações problemáticas antes mesmo de existir uma política que sustentasse a educação inclusiva em nosso estado.

O início do PEEDI, em 1999, gerou a necessidade da formação de multiplicadores e, então, a consolidação de uma equipe responsável pela formação dos primeiros a disseminar a proposta da educação inclusiva no estado de Goiás, tal como os turnos de discurso, a seguir, nos contam:

PM2 - Eu lembro da transição da educação de integração para inclusão no nosso estado. Aconteceu um encontro em 98, um fórum, que eu achei muito interessante, pois eu dou muito valor na experiência dos profissionais e eu ficava indignado com a gestão daquela época que não valorizava, discordava com as informações trazidas por eles. Então eu rebatia, não concordava com aquilo, parece que eles estavam sentindo que as coisas iriam mudar, foi quando em 99 chamaram o professor Romeu Sassaki para dar um curso de estudos em Educação Inclusiva para nossa equipe e assim vieram outros.

PM3 - Tiveram vários cursos. Nós fomos capacitados, mas nem todos os professores seguiram com as mudanças. Alguns ficaram só com a formação.

PM6 - Tivemos um curso em Anápolis e foi muito interessante, ele (Romeu Sassaki) falou muito bem sobre os princípios da educação inclusiva e de lá pra cá tudo foi mudando. Podemos dizer que ele foi um construtor do programa.

PM2 - O professor Romeu veio para dar uma palestra para o município de Goiânia e nesta, estava presente muitos convidados e então o professor Dalson viu que isso não podia ficar só no município de Goiânia. Ele, filho de pai surdo, envolveu-se muito e viu o que o pai passou em sua infância, tendo que ir para o Rio estudar. Então ele sempre se empenhou muito para educação dos surdos e então assistindo a esse encontro com o professor Romeu comecou a conversar conosco. Nós temos que chamar esse homem para falar com a gente para esclarecer melhor, por que gostei dele, ele traz uma realidade do Paraná, então a gente vai traz̧er ele, vai ouvir e vê o que é possivel a gente fazer, quero que ele fale sobre isso'.

PM7 - Foi dessa forma então que somente nós da superintendência, da secretaria, iniciamos uma discussão acerca da educação inclusiva no estado. Não havia professores da rede envolvidos ainda. Ai começou um a discussão do tema do encontro. PM6 - É verdade. E então em 99 eles se sentaram com a gente e falou, vamos propor, vamos ver o que a gente pode fazer. E então foi proposto esse redimensionamento do programa, e por isso tinha que fazer os projetos. Como nós trabalhávamos com os cegos, superdotados, surdos, trabalhávamos nessa parte especifica da educação inclusiva, tínhamos que fazer projetos direcionados ao atendimento.

PM2 - Nesta época o professor Dalson comecon a fazer as primeiras viagens, e então me chamaram para coordenar o projeto e eu até ajudei a elaborar, mas ao final 
quem elaborou não fui en e o projeto foi chamado de educação da escola inclusiva. Nesta época eu viajei com o professor Romeu em todas as subsecretarias.

PM7 - Iniciamos então em Goiânia com 17 escolas inclusivas e uma escola em cada subsecretaria do estado que era apoiada pela rede estadual. No outro ano isso expandiu e hoje todas as escolas são consideradas inclusivas em nosso estado.

O discurso revela que houve uma necessidade imediata de formação por parte dos professores responsáveis por implantar esse programa no estado de Goiás, o que foi efetivado mediante cursos proporcionados pela secretaria de educação, por meio da consultoria de alguns autores que escreviam sobre o assunto no Brasil e que já haviam efetivado políticas dessa natureza em outros estados.

Cabe, aqui, um alerta no que diz respeito à reflexão por parte dos professores, que revelam não terem havido resultados. Quando trabalhamos no âmbito da prática reflexiva, deixamos de ser meros participantes do processo e passamos a ser atores das mudanças em nossa práxis:

[...] o movimento da prática reflexiva rejeita a visão que trata o professor como mero participante passivo, sempre à mercê de diretrizes que emanam de cima para baixo, a partir das instâncias administrativas superiores da educação. Há um claro reconhecimento de que os professores são profissionais que devem desempenhar um papel ativo na formulação tanto nos propósitos e objetivos do seu trabalho, como nos meios para os atingir. (ARRUDA, 2001, p. 31)

No contexto da formação em serviço, após a implantação do projeto denominado "escola inclusiva" constituinte do PEEDI, iniciou-se um período de capacitação de professores pela coordenação de ensino especial, como nos revela os que fizeram e fazem parte desse tecido social:

PM1 - Nós ministramos cursos de formação continuada e às vezes sentimos que não conseguimos alcançar todo esse universo da educação inclusiva, pois temos muita rotatividade de professores por causa dos contratos temporários. Hoje nós já capacitamos oito mil professores, 'mas cadê eles?'

PM3 - Olha, talvez, nem a metade deles esteja em sala, mas ainda continuamos com os cursos, continuamos também em formação, continuamos assessorando, pois é um trabalho constante, contínuo e que precisa ampliar.

PM6 - É verdade, pois hoje estamos enquanto estado e município, estamos em parceria com as universidades como aqui na RPEI, mas esse é um trabalho que precisa crescer, iniciamos com um trabalho pequeno, mas ainda bem que já foi começado.

PM1 - A gente trabalha nos cursos com formação em rede, nós reunimos nas subsecretarias do estado e então a formação é repassada aos professores pelos membros das subsecretarias. Discutimos temas como: avaliação, currículo, flexibilização do curriculo, teorias de aprendizagem e outros temas. 
PM2 - O que observamos é que os professores ainda não se deram conta dessa diversidade, eles sabem que todos precisam estar na mesma sala de aula, mas acham que todos precisam estar no mesmo nivel, então por isso é que os cursos são importantes.

Esses resultados revelam que, desde que foi implantado o PEEDI no estado de Goiás, muitos professores já foram capacitados, em serviço; entretanto, é necessário que haja a continuidade de formação de qualidade que complementa e revoga reflexão sobre a prática, uma vez que, hoje, todas as escolas do estado são inclusivas.

Cabe ressaltar que, paralelamente à discussão a respeito da educação inclusiva no estado, vemos a sociedade do conhecimento configurando novos modos de ação a seus sujeitos e, com isto, desejando um ensino de ciências a todos. Portanto, é neste contexto que nasce a RPEI, objetivando contribuir para a melhoria do ensino de ciências no estado de Goiás por meio das interações sociais promovidas pela mesma.

Partindo desse pressuposto, vale lembrar que não existem "receitas", a serem seguidas pelos professores, capazes de promover essa formação para a cidadania no que diz respeito ao ensino de ciências no âmbito da educação inclusiva. Entretanto, é neste ponto que a RPEI está fazendo história no estado de Goiás. A RPEI foi formada por uma parceria dialógica, que conta com as participações: da Universidade Federal de Goiás (a perspectiva acadêmica: professores formadores, professores em formação inicial), especificamente o Instituto de Química e o programa de Mestrado em Educação em Ciências e Matemática (ao qual a proponente e coordenadora da Rede está vinculada e é modulada); da Secretaria de Educação do Estado de Goiás, por meio da Coordenação de Educação Especial (a perspectiva política e gestora), e da Associação de Surdos de Goiânia (a perspectiva da comunidade). A constituição da RPEI é algo que lhe confere uma característica singular. Essa assimetria na composição do grupo (não com a conotação hierárquica, mas quanto às distinções de cada esfera) lhe confere a possibilidade de um olhar bastante abrangente quanto ao tema (BENITE et al., 2009).

Hoje, a RPEI atua na formação inicial e continuada de professores para atuar na educação inclusiva no estado de Goiás; e tem sido local de reflexão a respeito da ação docente:

\begin{abstract}
A3 - É interessante observar que muitos de nós somos alunos em processo de formação inicial e continuada, vocês professores e gestores de políticas públicas da Rede Estadual de Ensino de Goiás e vocês professores formadores. Então sob esta ótica esta é uma experiência que parece ser produtiva já que atuamos em diferentes nivveis.
\end{abstract}

Para que a RPEI possa atingir o objetivo de se consolidar como um espaço que confronte concepções teóricas e práticas por meio da sinergia entre diversas vozes, defendemos que é por meio da participação coletiva que discursos individuais adquirem importância. Isso se fundamenta em nossa percepção de que o conhecimento elaborado na RPEI não resulta da interação direta entre as vozes pertencentes à RPEI, mas, sim, da participação dessas vozes na interação entre os sujeitos nessa rede social. 


\section{Algumas considerações}

A melhoria da formação dos professores depende, fundamentalmente, da evolução histórica da delineação do problema e da sistematização de pesquisas neste âmbito. Sendo assim, no estado de Goiás, desde a promulgação da Lei complementar n. 26 em 1998, muitos foram os avanços nesta política educacional. A tendência brasileira se repetiu em Goiás, uma vez que passamos da fase de completa exclusão das pessoas com necessidades educacionais especiais, para a fase da integração, e agora, mais recentemente, à fase da inclusão.

Com a implantação da educação inclusiva no estado a partir de 1999, a intensificação dos esforços para o cumprimento dessa política no estado levou a discussões que culminaram na melhoria da formação de professores que viessem a atuar nessa nova configuração educacional do estado.

Nesse sentido, a RPEI se torna um importante instrumento formativo (inicial e continuado), uma vez que propicia discussões no âmbito da educação inclusiva, por meio das interações sociais da tríade de professores (professores formadores, em formação inicial e continuada). A formação triádica, em nosso caso, levou professores em atuação a refletirem sobre o histórico da educação inclusiva no estado de Goiás, que puderam constatar os avanços nas políticas estaduais sobre educação inclusiva e nas realidades escolares. No mais, essa discussão serviu como processo de autorreflexão docente, que é um dos passos essenciais para o desenvolvimento de práticas docentes críticas e autônomas.

Além disso, a experiência desses docentes, narrada por intermédio do resgate histórico, serviu como espaço formativo para os alunos de graduação e pós-graduação, uma vez que puderam perceber a dinâmica teoria-prática no cotidiano de professores em atuação. É a partir desse tipo de discussões que estudantes podem ressignificar os contextos e as teorias discutidas durante suas formações na Universidade.

Assim, o principal ganho da RPEI é a promoção do debate crítico, com respeito às diferentes opiniões e constituição históricas de seus participantes. Embora a educação inclusiva esteja ainda "engatinhando", percebemos que os professores, atores do processo educacional, estão engajados em sua melhoria. Grandes percalços e dúvidas ainda existem. Por exemplo, os professores da Educação Básica mostraram algumas iniciativas que vêm sendo desenvolvidas, como os cursos de formação em serviço, por exemplo. Entretanto, a alta rotatividade de professores impede o maior aproveitamento desses cursos. Para sanar esse problema, é primordial que o governo aumente o número de professores efetivos e apoie ações formativas.

No caso do ensino de ciências, esbarramos, ainda, em dois grandes empecilhos: a dificuldade de transposição da linguagem científica em linguagem escolar acessível à realidade dos estudantes, e a falta de professores de ciências licenciados em suas áreas. Embora tenha havido, nos últimos anos, a expansão do número de vagas dos cursos de licenciatura em ciências, há baixo interesse de as pessoas os cursarem, uma vez que a desvalorização da carreira docente não torna os cursos atrativos. Mais uma vez, esbarramos nos clássicos problemas educacionais, que acabam por prejudicar a efetiva implantação da educação inclusiva. 


\section{Referências}

ALMEIDA, D. B. Do especial ao inclusivo?: um estudo da proposta de inclusão escolar da Rede Estadual de Goiás, no município de Goiânia. 2003. 204 f. Tese (Doutorado em Educação) - Faculdade de Educação, Universidade Estadual de Campinas, Campinas, 2003.

ARRUDA, S. M. Entre a inércia e a busca: reflexões sobre a formação em serviço de professores de física do ensino médio. 2001. 230 f. Tese (Doutorado em Educação) Faculdade de Educação, Universidade de São Paulo, São Paulo, 2001.

BAKHTIN, M. Marxismo e filosofia da linguagem. 12. ed. São Paulo: Hucitec, 2006.

BENITE, C. R. M. Discussão curricular a partir do tema energia numa perspectiva de intervenção na formação continuada de professores. 2009. 113 f. Dissertação (Mestrado em Educação em Ciências e Matemática) - Universidade Federal de Goiás, Goiânia, 2009.

BENITE, A. M. C. et al. Formação de professores de ciências em rede social: uma perspectiva dialógica na educação inclusiva. Revista Brasileira de Pesquisa em Educação em Ciências, Belo Horizonte, v. 9, n. 3, p. 1-21, 2009. Disponível em: <http:// revistas. if.usp.br/rbpec/article/viewFile/26/23 >. Acesso em: 21 mar. 2011.

Lei no. 9.394, de 20 de dezembro de 1996. Estabelece as diretrizes e bases da educação nacional. Diário Oficial da União, Brasilia, 23 dez. 1996, p. 27833. Disponível em: <https://www.planalto.gov.br/ccivil_03/Leis/L9394.htm>. Acesso em: 03 fev. 2015.

BRASIL. Conselho Nacional de Educação. Resolução CNE/CEB no 2, de 11 de setembro de 2001. Institui diretrizes nacionais para a educação especial na educação básica. Brasília, 2001. Disponível em: <http://portal.mec.gov.br/cne/arquivos/pdf/CEB0201.pdf>. Acesso em: 03 fev. 2015.

. Ministério da Educação e do Desporto. Secretaria de Educação Básica. Parâmetros curriculares nacionais para o ensino médio. Brasília, 2000.

BUENO, J. G. S. Crianças com necessidades educativas especiais, política educacional e a formação de professores: generalistas ou especialistas? Revista Brasileira de Educação Especial Piracicaba, v. 3, n. 5, p. 7-25, 1999. Disponível em: <http://www.abpee.net/ homepageabpee04_06/artigos_em_pdf/revista5numero1pdf/r5_art01.pdf $>$. Acesso em: 03 fev. 2015.

CAMPOS, S.; PESSOA, V. I. F. Discutindo a formação de professoras e de professores com Donald Schön. In: GERALDI, C. M. G.; FIORENTINI, D.; PEREIRA, E. M. A. (Org.). Cartografias do trabalho docente: professor(a)-pesquisador(a). Campinas: Mercado de Letras: Associação de Leitura do Brasil, 1998. p. 183-206.

CARVALHO, R. E. Educação inclusiva: com os pingos nos “is". 5. ed. Porto Alegre: Mediação, 2004.

DRIVER, R. et al. Construindo conhecimento na sala de aula. Química Nova na Escola, São Paulo, n. 9, p. 31-40, 1999. 
ECHEVERRÍA, A. R.; BENITE, A. M. C.; SOARES, M. H. F. B. A pesquisa na formação inicial de professores de química: a experiência do Instituto de Química da Universidade Federal de Goiás. In: REUNIÃO ANUAL DA SOCIEDADE BRASILEIRA DE QUímICA, 30., 2007, Águas de Lindóia. Anais... Águas de Lindóia: SBQ, 2007. Disponível em: <www.sbq.org.br/30ra/Workshop\%20UFG.pdf>. Acesso em: 22 mar. 2011.

GLAT, R.; NOGUEIRA, M. L. L. Políticas educacionais e a formação de professores para a educação inclusiva no Brasil. Comunicações, Piracicaba, v. 10, n. 1, p. 134-141, 2003. Disponível em: < https://www.metodista.br/revistas/revistas-unimep/index.php/ comunicacao/article/view/1647/1055>. Acesso em: 03 fev. 2015.

GOIÁS. Lei complementar no 62, de 09 de outubro de 2008. Aprova o plano estadual de educação para o decênio 2008/2017 e dá outras providências. Diário Oficial do Estado de Goiás, Goiânia, 17 out. 2008. Disponível em: <http://www.gabinetecivil.go.gov.br/pagina_ leis.php?id=7705>. Acesso em: 03 fev. 2015.

. Secretaria da Educação. Educação em dados 2000-2006: professores em exercício por dependência administrativa. [Goiânia], 2006. Disponível em: <http://www.educacao. go.gov.br/portal/educacao/professores_emxercicio.asp> Acesso em: 18 mar. 2011.

Secretaria de Educação. Superintendência de Ensino Especial. Programa estadual de educação para a diversidade numa perspectiva inclusiva no estado de Goiás, Brasil. Goiânia, Secretaria da Educação, 2004.

GONÇALVES, T. O.; GONÇALVES, T. V. O. Reflexões sobre uma prática docente situada: buscando novas perspectivas para a formação de professores. In: GERALDI, C. M. G.; FIORENTINI, D.; PEREIRA, E. M. A. (Org.). Cartografias do trabalho docente: professor(a)-pesquisador(a). Campinas: Mercado de Letras: Associação de Leitura do Brasil, 1998. p. 105-134.

HALL, B. L. O saber como mercadoria e a investigação participativa. Perspesctivas, Lisboa, v. 9, n. 4, p. 395-411, 1979.

HAMES, C.; ZANON, L. B.; WIRZBICKI, S. M. A importância das interações de sujeitos num processo coletivo de reconstrução curricular em ciências naturais. In: ENCONTRO REGIONAL SUL DE ENSINO DE BIOLOGIA, 2., 2006, Florianópolis. Atas... Florianópolis: UFSC, 2006. p. 1-12.

MACHADO, A. H. Aula de química: discurso e conhecimento. Ijuí: Ed. Unijuí, 1999.

MENDES, E. Radicalization of the debate on school inclusion in Brazil. Revista Brasileira de Educação, Rio de Janeiro, v. 11, n. 33, p. 387-405, 2006.

MORIN, E. Ciência com consciência. 8. ed. Rio de Janeiro: Bertrand Brasil, 2005.

NÓVOA, A. Os professores e a sua formação. 2. ed. Lisboa: Dom Quixote, 1995.

SANT'ANA, I. M. Educação inclusiva: concepções de professores e diretores. Revista

Psicologia em Estudo, Maringá, v. 10, n. 12, p. 227-234, 2005. 
SANTOS, W. L.; SCHNETZLER, R. P. Educação em química: compromisso com a cidadania. Ijuí: Ed. Unijuí, 2003.

SASSAKI, R. K. A Educação inclusiva no estado de Goiás: relato de uma experiência. In: COORDINATORS' notebook : a infância em debate: perspectivas contemporâneas. Brasília: UNESCO: Fundação ORSA, 2003. p. 33-38. (Série Coordinators’ notebook, 1).

SCHNETZLER, R. P. Concepções e alertas sobre formação continuada de professores de química. Química Nova na Escola, São Paulo, n. 16, p. 15-20, 2002.

SCHÖN, D. A. La formación de profisionales reflexivos: hacia um nuevo diseño de la enseñanza y el aprendizaje en las profesionales. Madrid: Paidós, 1987.

E1 professional reflexive: cómo piensan los profesionales cuando actúan.

Barcelona: Paidós, 1998.

STAINBACK, S.; STAINBACK, W. Inclusão: um guia para educadores. Porto Alegre: Artes Médicas Sul, 1999.

UNESCO. Declaração mundial sobre educação para todos: satisfação das necessidades básicas de aprendizagem. Jomtien, 1990. Disponível em: <http://unesdoc. unesco.org/images/0008/000862/086291por.pdf> Acesso em: 03 fev. 2015.

VILELA-RIBEIRO, E. B.; BENITE, A. M. C. A educação inclusiva na percepção dos professores de química. Ciência \& Educação, Bauru, v. 16, n. 3, p. 585-594, 2010.

VIGOTSKY, L. S. A construção do pensamento e da linguagem. São Paulo: Martins Fontes, 2001.

ZEICHNER, K. M. Para além da divisão entre professor-pesquisador e pesquisador acadêmico. In: GERALDI, C. M. G.; FIORENTINI, D.; PEREIRA, E. M. A. (Org.). Cartografias do trabalho docente: professor(a)-pesquisador(a). Campinas: Mercado de Letras: Associação de Leitura do Brasil, 1998. p. 207-236. 